\title{
Cancer incidence attributable to inadequate physical activity in Alberta in 2012
}

\author{
Darren R. Brenner PhD, Abbey E. Poirier MSc, Anne Grundy PhD, Farah Khandwala MSc, \\ Alison McFadden BSc, Christine M. Friedenreich PhD
}

\section{Abstract}

Background: Physical inactivity has been consistently associated with increased risk of colorectal, endometrial, breast (in postmenopausal women), prostate, lung and ovarian cancers. The objective of the current analysis was to estimate the proportion and absolute number of site-specific cancer cases attributable to inadequate physical activity in Alberta in 2012.

\begin{abstract}
Methods: We used population attributable risks to estimate the proportion of each site-specific cancer attributable to inactivity. Relative risk estimates were obtained from the epidemiological literature, and prevalence estimates were calculated with the use of data from the Canadian Community Health Survey cycle 2.1 (2003). Respondents who acquired 1.5-2.9 kcal/kg per day and less than $1.5 \mathrm{kcal} / \mathrm{kg}$ per day of physical activity were classified as moderately active and inactive, respectively, and both levels were considered inadequate for mitigating cancer risks. We obtained age-, sex- and site-specific cancer incidence data from the Alberta Cancer Registry for 2012.
\end{abstract}

Results: About $59 \%-75 \%$ of men and $69 \%-78 \%$ of women did not engage in adequate physical activity. Overall, $13.8 \%$ of cancers across all associated cancers were estimated to be attributable to inadequate physical activity, representing $7.2 \%$ of all cancers diagnosed in Alberta in 2012. Suboptimal levels of physical activity had a greater impact among women: the proportion of all associated cancers attributable to inadequate physical activity was $18.3 \%$ for women and $9.9 \%$ for men.

Interpretation: A substantial proportion of cancer cases diagnosed in Alberta were estimated to be attributable to inadequate physical activity. With the high prevalence of physical inactivity among adults in the province, developing strategies to increase physical activity levels could have a notable impact on reducing future cancer burden in Alberta.

T n 2010, the World Health Organization identified physical inactivity as the fourth-leading cause of global mortality. ${ }^{1}$ In Canada, levels of physical inactivity remained high and relatively stable between 2003 and 2014. ${ }^{2}$ Based on the 2007-2008 Canadian Community Health Survey (CCHS), the Public Health Agency of Canada estimated that $53.1 \%$ of women and $49.2 \%$ of men in this country are classified as physically inactive, as measured by leisure time energy expenditure. ${ }^{3}$ Colley and colleagues ${ }^{4}$ reported in 2011 that $85 \%$ of Canadian adults did not meet Canada's physical activity recommendation of at least 150 minutes per week of moderate to vigorous physical activity, accumulated in bouts lasting at least 10 minutes using accelerometrybased measurement.

One of the major implications of increasing levels of physical inactivity is the potential impact on the incidence of several common cancers. The World Cancer Research Fund concluded in its 2007 report that the evidence associating higher levels of physical activity and lowered cancer risk was "convincing" for colon cancer and "probable" for breast can- cer in postmenopausal women and endometrial cancer. ${ }^{5}$ It has been estimated that $21 \%-25 \%$ of the burden of breast and colon cancer is attributable to physical inactivity. ${ }^{1}$ In addition, there is strong evidence that the risk of development of lung, ${ }^{6}$ ovarian $^{7}$ and prostate cancer ${ }^{8,9}$ is linked to physical activity levels. In Alberta in 2012, there were 8215 incident cases of cancer at sites shown to be associated with inadequate physical activity..$^{10}$

Studies of population attributable risk in the United Kingdom and Australia have estimated that 3275 and 1814 incident cancer cases, respectively, could be attributable to inadequate

\section{Competing interests: None declared.}

This article has been peer reviewed.

Correspondence to: Darren Brenner, Darren.Brenner@ albertahealthservices.ca

CMAJ Open 2017. DOI:10.9778/cmajo.20160044 
levels of physical activity. ${ }^{11,12}$ However, these studies considered only colon, breast and endometrial cancers. We previously estimated that, in Canada, $5.8 \%$ and $10.2 \%$ of cancers in men and women, respectively, could be attributed to inadequate physical activity (energy expenditure $<3 \mathrm{kcal} / \mathrm{kg}$ per day). ${ }^{13}$ The objective of this analysis was to estimate the proportion and absolute number of site-specific cancer cases attributable to inadequate physical activity in Alberta in 2012.

\section{Methods}

This paper is part of a series of exposure-specific manuscripts concerning the proportion of cancer cases attributable to modifiable lifestyle and environmental risk factors in the general population of Alberta. The methodologic framework for the series' methods has been previously described. ${ }^{14}$

\section{Latency period}

The cancer risk associated with inadequate physical activity is understood to be the result of past exposure to inadequate physical activity. Thus, we identified a 7- to 10 -year latency period based on previous literature. ${ }^{13}$ As has been previously described, ${ }^{14}$ we considered the theoretical latency period to be the time between initiation of exposure and cancer diagnosis, and the measured latency period to be the time between exposure measurement and cancer diagnosis. We used data from CCHS cycle 2.1 (2003) to estimate the prevalence of physical inactivity among Alberta adults as this cycle corresponded to the midpoint of the latency period suggested by cohort studies for the cancer sites of interest. ${ }^{15-19}$

\section{Prevalence of exposure}

The CCHS collected information on the nature, frequency and duration of leisure-time physical activity. The survey is considered representative of the general Canadian population excluding full-time members of the Canadian Armed Forces, people living on reserves or other Aboriginal settlements, and people living in institutions. Details of the methods used for the CCHS were published previously. ${ }^{20}$

In the CCHS, physical activity levels were based on leisure time physical activity only. The derived daily energy expenditure variable was based on the number of times a respondent engaged in a given activity each day multiplied by the average duration of the activity. This product was then multiplied by the energy cost (kilocalories per kilogram of body weight per hour) of the activity. Questions on leisure time physical activity from the 2003 CCHS and the method for estimating daily energy expenditure can be found in Appendix 1, Supplementary Table 1 (available at www.cmajopen.ca/content/5/2/E338/suppl/DC1). Respondents were classified as physically active (energy expenditure $\geq 3.0 \mathrm{kcal} /$ $\mathrm{kg}$ per day), moderately active $(1.5-2.9 \mathrm{kcal} / \mathrm{kg}$ per day) or inactive (<1.5 kcal/kg per day). The "physically active" category generally reflects a level of regular, daily activity for at least 30 minutes a day. In terms of cancer prevention, being in the moderately active group is suboptimal; ${ }^{21}$ thus, this category is referred to as "moderately inactive" in this analysis. Moderate inactivity and inactivity were both considered as inadequate physical activity levels, and we analyzed these 2 categories independently and as a combined variable in order to determine the population attributable risks of cancer due to inadequate physical activity.

\section{Risk estimates}

The cancer sites with the most consistent evidence of association with inadequate physical activity include the colon, endometrium, breast, prostate, lung and ovary. ${ }^{22}$ We took risk estimates used for estimating population attributable risks of cancers of these sites from recent reviews and metaanalyses $^{5-9,23-28}$ (Table 1). Detailed information on the studies from which we abstracted the relative risks (RRs) is presented in Appendix 1, Supplementary Table 2. The same RRs were

Table 1: Risk estimates for risk associated with inadequate physical activity by cancer site of interest

\begin{tabular}{|c|c|c|c|c|c|c|}
\hline \multirow[b]{2}{*}{ Cancer site } & \multirow[b]{2}{*}{ Sex } & \multicolumn{2}{|c|}{ Activity level; relative risk } & \multirow[b]{2}{*}{ Source } & \multicolumn{2}{|c|}{$\begin{array}{c}\text { Activity level; excess relative } \\
\text { risk }\end{array}$} \\
\hline & & Active* $^{*}$ & $\begin{array}{l}\text { Moderately } \\
\text { active† }\end{array}$ & & $\begin{array}{l}\text { Moderately } \\
\text { inactive† }\end{array}$ & Inactive§ \\
\hline Lung & Both & 0.70 & 0.84 & Tardon et al. ${ }^{6} 2005$ & 1.20 & 1.43 \\
\hline Colorectum & Both & 0.76 & 0.87 & $\begin{array}{l}\text { Wolin et al. }{ }^{23} 2009 \text { and Wolin et al. } .^{27} \\
2011\end{array}$ & 1.15 & 1.32 \\
\hline Prostate & Men & 0.95 & 0.98 & Liu et al. ${ }^{9} 2011$, Leitzmann ${ }^{8} 2011$ & 1.03 & 1.05 \\
\hline Breastๆ & Women & 0.75 & 0.87 & $\begin{array}{l}\text { Friedenreich et al. }{ }^{24} 2008 \text {, Lynch et } \\
\text { al. }{ }^{28} 2011\end{array}$ & 1.16 & 1.33 \\
\hline Ovary & Women & 0.81 & 0.90 & Olsen et al. ${ }^{5} 2007$ & 1.11 & 1.24 \\
\hline Endometrium & Women & 0.70 & 0.84 & Cust et al. ${ }^{26} 2011$ & 1.20 & 1.43 \\
\hline
\end{tabular}


also used in our previous paper on the attributable risks of cancer due to physical inactivity in the Canadian population. ${ }^{13}$ We abstracted and further screened relevant RRs, and those applicable to our prevalence data were selected for estimation of population attributable risk. To quantify the effect of physical inactivity, we estimated the increased risk associated with being physically inactive as ( 1 / RR) - 1 .

\section{Estimation of population attributable risk}

We used the method applied by Parkin ${ }^{11}$ to estimate population attributable risks associated with being either moderately inactive or inactive, using the following equation:

Population attributable risk $=\left[\left(p e_{1} \times E R R_{1}\right)+\left(p e_{2} \times E R R_{2}\right)\right] / 1+$ $\left[\left(p e_{1} \times E R R_{1}\right)+\left(p e_{2} \times E R R_{2}\right)\right]$

where $p e_{1}$ is the prevalence of moderate inactivity, $p e_{2}$ is the prevalence of inactivity, and $E R R_{1}$ and $E R R_{2}$ denote the excess RRs associated with moderate inactivity and inactivity, respectively.

We then multiplied the population attributable risks by the number of incident cancer cases of interest in Alberta in 2012, obtained from the Alberta Cancer Registry, to determine the excess attributable cases for each cancer site. For breast cancer in postmenopausal women, only breast cancers diagnosed after 55 years of age were included, as the median age at menmenopause is 50-51 years among North American women. ${ }^{29,30}$ We estimated the total proportion of cancer cases estimated to be attributable to inadequate physical activity at each individual cancer site as the total number of excess attributable cases for that cancer across all age groups divided by the total number of observed cancers at that site for both men and women individually and combined.

All analyses were conducted with the use of RStudio version 0.98.1080 (R Studio, Inc.).

\section{Ethics approval}

Ethics approval was obtained from the Conjoint Health Research Ethics Board, University of Calgary.

\section{Results}

\section{Prevalence}

Prevalence estimates of moderate inactivity and inactivity among men and women in Alberta are presented in Table 2. Overall, $41.2 \%$ (95\% confidence interval [CI] 38.6-43.8) to $53.0 \%$ (95\% CI 50.0-56.0) of adults were physically inactive, and $21.8 \%$ (95\% CI $19.3-24.2)$ to $28.6 \%$ (95\% CI 25.8-31.4) were moderately inactive. Higher proportions of adults in older than in younger age groups were physically inactive; however, the differences were not significant for all age groups. The prevalence of inactivity appeared to be slightly higher among women than men. Cancer-site-specific population attributable risk

The numbers and proportions of cancer cases for specific cancer sites attributable to moderate inactivity and inactivity combined are presented in Table 3. Specific cancer incidence estimates attributable to moderate inactivity and inactivity are presented separately in Appendix 1, Supplementary Tables 3 and 4. Among different cancer sites, the attributable proportions of cases were highest for lung cancer $(18.1 \%-21.2 \%)$ and endometrial cancer $(19.3 \%-22.0 \%)$, across all age groups. In terms of absolute numbers, the sites most affected by inadequate physical activity were the lung $(n=192)$ and colorectum $(n=175)$ for men and the breast $(n=221)$ and lung $(n=$ 210) for women, mainly owing to the greater total incidence for these cancer sites (Figure 1). For prostate cancer, the RR associated with inadequate physical activity was low (Table 1); thus, despite a much higher total incidence, the attributable proportion of cases $(n=69)$ was much lower than for other high-incidence sites (Figure 1). At the time of exposure, people aged 50 or more were most affected by lack of adequate physical activity (Table 3). This is a result of the greater total incidence of being less active among the older population.

\section{Overall population attributable risk}

The total number and proportion of excess attributable cases of cancer for each site are summarized in Table 4. Overall, 13.8\% of cancers $(n=1135)$ across all associated sites were estimated to be attributable to inadequate physical activity. The proportion of attributable cancers was higher for women $(697$ [18.3\%]) than men (436 [9.9\%]). This is a result of a greater number of excess attributable cases in women over a smaller number of total observed cases (Table 4). We estimated that, overall, 7.2\% of all cancer cases diagnosed in Alberta in 2012 could be attributable to inadequate physical activity; again, this estimate was higher for women (9.1\%) than men (5.4\%).

\begin{tabular}{|c|c|c|}
\hline \multirow[b]{2}{*}{ Sex; age, yr } & \multicolumn{2}{|c|}{ Activity level; prevalence $(95 \% \mathrm{Cl})$} \\
\hline & Moderately inactive & Inactive \\
\hline \multicolumn{3}{|l|}{ Men } \\
\hline 20-34 & $21.6(18.3-24.9)$ & $37.8(34.1-41.6)$ \\
\hline $35-49$ & $24.4(21.1-27.7)$ & $48.8(44.9-52.6)$ \\
\hline $50-64$ & $28.7(24.5-33.0)$ & $46.6(42.2-51.1)$ \\
\hline$\geq 65$ & $21.0(17.3-24.8)$ & $49.4(44.9-53.9)$ \\
\hline \multicolumn{3}{|l|}{ Women } \\
\hline $20-34$ & $24.6(21.7-27.5)$ & $44.7(41.2-48.3)$ \\
\hline $35-49$ & $24.6(21.0-28.0)$ & $44.0(39.9-48.0)$ \\
\hline $50-64$ & $28.5(24.8-32.2)$ & $49.3(45.1-53.4)$ \\
\hline$\geq 65$ & $22.4(19.0-25.7)$ & $56.0(51.9-60.0)$ \\
\hline \multicolumn{3}{|l|}{ Total } \\
\hline 20-34 & $23.1(20.9-25.3)$ & $41.2(38.6-43.8)$ \\
\hline $35-49$ & $24.5(22.1-36.9)$ & $46.4(43.6-49.2)$ \\
\hline $50-64$ & $28.6(25.8-31.4)$ & $48.0(44.9-51.0)$ \\
\hline$\geq 65$ & $21.8(19.3-24.2)$ & $53.0(50.0-56.0)$ \\
\hline
\end{tabular}


When we removed lung cancer from the analyses, the proportion of attributable cases for the remaining 5 sites increased slightly, to $14.3 \%$, and the overall proportion of attributable cases was reduced to $5.7 \%$ for all cancers (data not shown).

\section{Interpretation}

In the current analysis, an estimated $7.2 \%(n=1135)$ of all cancer cases, representing $13.8 \%$ of associated cancer cases, diagnosed in Alberta in 2012 were estimated to be attributable to inadequate physical activity. The overall cancer burden due to inadequate physical activity was much greater among women $(9.1 \%$ of all cancers, $n=697)$ than men $(5.4 \%$ of all cancers, $n=436$ ). This sex difference was expected, as 3 of the cancer sites associated with inadequate physical activity are female specific (breast, endometrium and ovary).

The current site-specific estimates for Alberta are comparable to previous Canadian estimates. Brenner ${ }^{13}$ estimated that $21.1 \%$ of lung or bronchus, $16.8 \%$ of colon, $3.1 \%$ of prostate, $18.5 \%$ of breast (in postmenopausal women), $22.4 \%$ of endometrial and $13.8 \%$ of ovarian cancers could be attributed to suboptimal leisure time physical activity in Canada in 2007. The corresponding estimates in the current study are
$20.6 \%, 16.1 \%, 2.9 \%, 17.4 \%, 20.5 \%$ and $12.7 \%$. Similar risk estimates for colon $(19.9 \%)$ and breast $(11.0 \%)$ cancer burdens associated with physical inactivity in Canada were also reported by Katzmarzyk and colleagues. ${ }^{31}$ The International Agency for Research on Cancer summarized in its 2002 and 2009 reports that $13 \%-14 \%$ of colon cancer, $11 \%$ of breast cancer in postmenopausal women and $30 \%$ of endometrial cancer could be attributable to physical inactivity. ${ }^{32,33}$ Our use of the method developed by Parkin ${ }^{11}$ means that our results can be compared directly to those of Parkin and of other investigators who have used Parkin's method. The estimates in the UK and Australian studies were quite a bit lower than the current estimates: Parkin's ${ }^{11}$ estimates for colon, breast and endometrial cancer attributable to inadequate physical exercise ranged from $3.4 \%-5.3 \%$, and estimates for the same sites in the Australian study ranged from $6.0 \%-7.8 \% .{ }^{12}$ However, both Parkin ${ }^{11}$ and Olsen and colleagues ${ }^{12}$ used minutes of activity per day rather than a comprehensive measure of daily energy expenditure, which reduced the magnitude of the protective effect of physical activity. This was reflected in the RRs used to calculate the population attributable risk and contributed to the lower estimates.

Overall, $13.8 \%$ of cases among associated sites and $7.2 \%$ of cases among all cancers in Alberta in 2012 could have been

Table 3: Numbers and proportions of incident cancer cases attributable to inadequate physical activity in Alberta in 2012

\begin{tabular}{|c|c|c|c|c|c|c|c|c|c|c|c|c|c|c|c|c|c|c|c|}
\hline \multirow{3}{*}{$\begin{array}{l}\text { Sex; } \\
\text { age at } \\
\text { exposure } \\
\text { yr }\end{array}$} & \multirow{3}{*}{$\begin{array}{c}\text { Age at } \\
\text { outcome, } \\
\text { yr }\end{array}$} & \multicolumn{18}{|c|}{ Cancer site } \\
\hline & & \multicolumn{3}{|c|}{ Lung } & \multicolumn{3}{|c|}{ Colorectum } & \multicolumn{3}{|c|}{ Prostate } & \multicolumn{3}{|c|}{ Breast } & \multicolumn{3}{|c|}{ Ovary } & \multicolumn{3}{|c|}{ Endometrium } \\
\hline & & Obs.* & $\begin{array}{c}\text { PAR, } \\
\% \dagger\end{array}$ & EAC‡ & Obs. & PAR, \% & EAC & Obs. & PAR, \% & EAC & Obs. & $\begin{array}{c}\text { PAR, } \\
\%\end{array}$ & EAC & Obs. & PAR, \% & EAC & Obs. & PAR, \% & EAC \\
\hline \multicolumn{20}{|l|}{ Men } \\
\hline 20-34 & $30-44$ & 13 & 16.9 & 2 & 37 & 13.2 & 5 & 18 & 2.4 & - & & & & & & & & & \\
\hline $35-49$ & $45-59$ & 141 & 20.4 & 29 & 276 & 16.0 & 44 & 591 & 3.0 & 18 & & & & & & & & & \\
\hline $50-64$ & $60-74$ & 468 & 20.3 & 95 & 454 & 16.0 & 73 & 1240 & 2.9 & 37 & & & & & & & & & \\
\hline$\geq 65$ & $\geq 75$ & 331 & 20.1 & 67 & 338 & 15.8 & 53 & 504 & 2.9 & 15 & & & & & & & & & \\
\hline Total & & 953 & & 192 & 1105 & & 175 & 2353 & & 69 & & & & & & & & & \\
\hline \multicolumn{20}{|l|}{ Women } \\
\hline 20-34 & $30-44$ & 8 & 19.3 & 2 & 35 & 15.1 & 5 & & & & - & - & - & 15 & 11.7 & 2 & 25 & 19.3 & 5 \\
\hline $35-49$ & $45-59$ & 171 & 19.1 & 33 & 193 & 14.9 & 29 & & & & - & - & - & 62 & 11.5 & 7 & 175 & 19.1 & 33 \\
\hline $50-64$ & $60-74$ & 479 & 21.0 & 101 & 292 & 16.5 & 48 & & & & 840 & 17.1 & 144 & 64 & 12.8 & 8 & 230 & 21.0 & 48 \\
\hline$\geq 65$ & $\geq 75$ & 341 & 22.0 & 75 & 326 & 17.4 & 57 & & & & 427 & 18.0 & 77 & 48 & 13.5 & 6 & 73 & 22.0 & 16 \\
\hline Total & & 999 & & 210 & 846 & & 139 & & & & 1267 & & 221 & 189 & & 24 & 503 & & 103 \\
\hline \multicolumn{20}{|l|}{ Total } \\
\hline $20-34$ & $30-44$ & 21 & 18.1 & 4 & 72 & 14.1 & 10 & 18 & 2.4 & - & - & - & - & 15 & 11.7 & 2 & 25 & 19.3 & 5 \\
\hline $35-49$ & $45-59$ & 312 & 19.7 & 62 & 469 & 15.5 & 73 & 591 & 3.0 & 18 & - & - & - & 62 & 11.5 & 7 & 175 & 19.1 & 33 \\
\hline $50-64$ & $60-74$ & 947 & 20.6 & 196 & 746 & 16.3 & 121 & 1240 & 2.9 & 37 & 840 & 17.1 & 144 & 64 & 12.8 & 8 & 230 & 21.0 & 48 \\
\hline$\geq 65$ & $\geq 75$ & 672 & 21.2 & 142 & 664 & 16.7 & 111 & 504 & 2.9 & 15 & 427 & 18.0 & 77 & 48 & 13.5 & 6 & 73 & 22.0 & 16 \\
\hline Total & & 1952 & & 403 & 1951 & & 315 & 2353 & & 69 & 1267 & & 221 & 189 & & 24 & 503 & & 103 \\
\hline $\begin{array}{l}\text { Note: EA } \\
{ }^{*} \text { Cases } r \\
\text { †PAR rep } \\
\text { †Excess }\end{array}$ & $\begin{array}{l}\text { excess a } \\
\text { ent the } \\
\text { nts the } \\
\text { utable c }\end{array}$ & $\begin{array}{l}\text { ttributabl } \\
\text { total num } \\
\text { proportio } \\
\text { cases rep }\end{array}$ & $\begin{array}{l}\text { cases } \\
\text { er of } c \\
\text { of can } \\
\text { sent } t\end{array}$ & $\begin{array}{l}\text { due to } \\
\text { ases of } \\
\text { cer case } \\
\text { he numb }\end{array}$ & $\begin{array}{l}\text { osure } \\
\text { ch car } \\
\text { ttribut }\end{array}$ & $\begin{array}{l}\text { Obs. = to } \\
\text { ncer type } \\
\text { table to in } \\
\text { ses attribu }\end{array}$ & $\begin{array}{l}\text { otal nu } \\
\text { in } 201 \\
\text { hadequ }\end{array}$ & er of ob & bserved c & cases & $\begin{array}{l}\text { age-se } \\
\text { tely ina }\end{array}$ & ex gro & $\begin{array}{l}\text { PAR } \\
\text { inac }\end{array}$ & pulati & ion attribut & & & & \\
\hline
\end{tabular}


preventable with increased physical activity levels. These numbers are similar to those reported by Brenner ${ }^{13}$ (14.7\% and $7.9 \%$, respectively). Friedenreich and colleagues ${ }^{34}$ exam- $^{-}$ ined the cancer burden due to physical inactivity in Europe and estimated that about $19 \%$ of associated cancers at the same sites could be prevented by increased physical activity.

The effect of physical inactivity on rates of lung cancer may be confounded by smoking or chronic lung disease, as smokers or people with pulmonary disease, who are at increased risk for lung cancer, are more likely to have reduced levels of physical activity. ${ }^{5}$ When we removed lung cancer from the analyses, the proportion of attributable cases for the remaining 5 sites increased slightly, to $14.3 \%$, and the overall proportion of attributable cases was reduced to $5.7 \%$ for all cancers.

\section{Limitations}

Our analyses are limited by several factors. We considered only leisure time physical activity, and therefore physical activity related to occupation or transportation was not included. In addition, although differences in risk and latency period may exist between men and women, we did not account for these differences in our analysis. We abstracted risk estimates from meta-analyses and pooled analyses, which may not reflect the risk for the adult Canadian population, as these estimates are pooled across various populations.

Many studies included in the meta-analyses adjusted for body mass index when estimating the risk associated with physical inactivity. $7,24,26$ Thus, physical activity appears to have effects on cancer risk independent of that of body weight. In a separate analysis, we estimated the cancer burden attributable to overweight and obesity. ${ }^{35}$ Body weight and physical activity are highly related. As sustained physical inactivity combined with excess energy intake can lead to overweight and obesity, it is likely that there is overlap in the number of attributable cases estimated. Thus, the population attributable risks associated with physical inactivity and excess body weight should not be combined, and the attributable fraction estimates should be interpreted with caution.

The current estimate of cancer burden associated with inadequate physical activity may be an underestimate as the prevalence estimates relied on the use of self-reported data from the CCHS. In our previous study of population attribut-

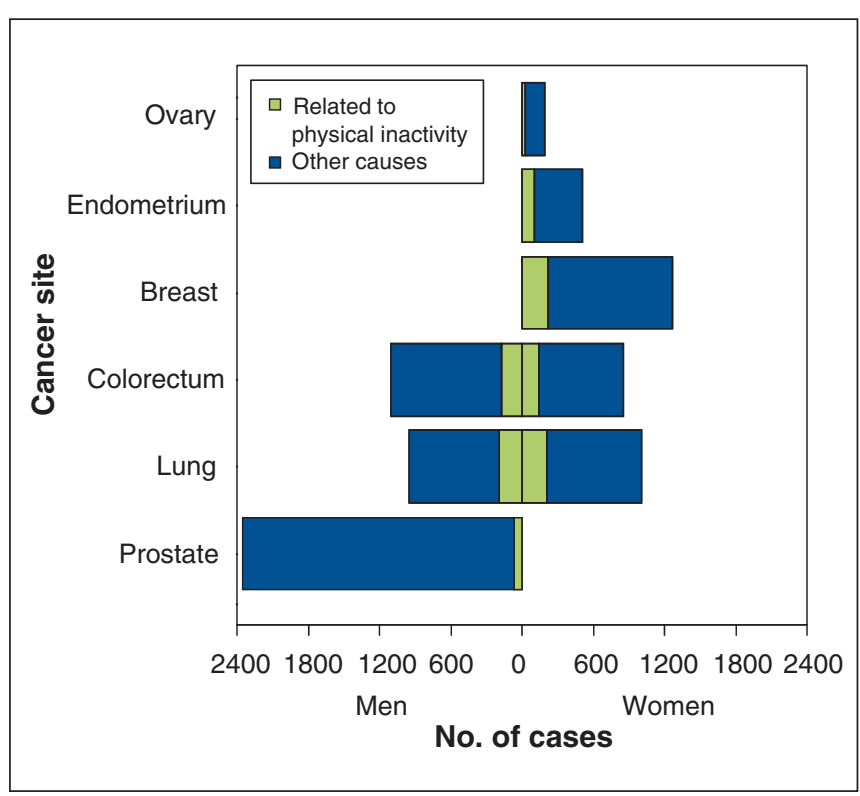

Figure 1: Number of cancer cases attributable to physical inactivity and other causes in Alberta in 2012.

Table 4: Summary of cases and proportions of cancer in Alberta adults in 2012 attributable to inadequate physical activity

\begin{tabular}{|c|c|c|c|c|c|c|c|c|c|}
\hline Cancer site & $\begin{array}{l}\text { Observed } \\
\text { cases }^{*}\end{array}$ & $\begin{array}{l}\text { Excess } \\
\text { attributable } \\
\text { cases† }\end{array}$ & $\begin{array}{c}\% \\
\text { attributable }\end{array}$ & $\begin{array}{l}\text { Observed } \\
\text { cases }\end{array}$ & $\begin{array}{l}\text { Excess } \\
\text { attributable } \\
\text { cases }\end{array}$ & $\begin{array}{c}\% \\
\text { attributable }\end{array}$ & $\begin{array}{l}\text { Observed } \\
\text { cases }\end{array}$ & $\begin{array}{c}\text { Excess } \\
\text { attributable } \\
\text { cases }\end{array}$ & $\begin{array}{c}\% \\
\text { attributable }\end{array}$ \\
\hline Prostate & 2353 & 69 & 2.9 & 2353 & 69 & 2.9 & - & - & - \\
\hline Breast§ & 1267 & 221 & 17.4 & - & - & - & 1267 & 221 & 17.4 \\
\hline Colorectum & 1951 & 315 & 16.1 & 1105 & 175 & 15.8 & 846 & 139 & 16.4 \\
\hline Endometrium & 503 & 103 & 20.5 & - & - & - & 503 & 103 & 20.5 \\
\hline Ovary & 189 & 24 & 12.7 & - & - & - & 189 & 24 & 12.7 \\
\hline $\begin{array}{l}\text { All associated } \\
\text { cancers } \|\end{array}$ & 8215 & 1135 & 13.8 & 4411 & 436 & 9.9 & 3804 & 697 & 18.3 \\
\hline
\end{tabular}


able risk, sensitivity analysis of Canadian data from the CCHS showed that, by using bias-adjusted prevalence estimates based on accelerometer data from the 2008 Canadian Health Measures Survey, the total cancer burden attributable to inadequate physical activity increased from $7.9 \%$ to $10.7 \% .{ }^{13}$ In addition, in the current analysis, we excluded cancer sites for which the evidence of association is suggestive but not yet fully developed, such as the pancreas, ${ }^{5}$ kidney $^{36}$ and liver. ${ }^{37}$ Thus, the overall burden of cancer in Alberta associated with physical inactivity is likely to be higher than the estimates reported here. Despite the limitations associated with selfreported data, CCHS data provided provincially representative prevalence estimates, as the survey's sampling frame represents $96 \%-98 \%$ of the Canadian adult population with the exception of a few specific populations (e.g., Aboriginal Canadians living on reserves and people living on Crown land or in military facilities).

\section{Conclusion}

We estimated that 1135 cancer cases, equivalent to over 7\% of all cancers, diagnosed in Alberta in 2012 were attributable to inadequate physical activity. With a high prevalence (> 70\%) of suboptimal physical activity among adults in the province, developing targeted strategies to encourage people, particularly women and adults 50 years of age or older, to engage in sustained adequate physical activity could have great potential in reducing cancer burden in Alberta.

\section{References}

1. Global recommendations on physical activity for health. Geneva: World Health Organization; 2010.

2. Statistics Canada. Table 105-0501 - Health indicator profile, annual estimates, by age group and sex, Canada, provinces, territories, health regions (2013 boundaries) and peer groups, occasional (modified 2016 Apr. 22). CANSIM database.

3. Obesity in Canada. Toronto: Public Health Agency of Canada/Canadian Institute for Health Information; 2011. Available: www.phac-aspc.gc.ca/hp-ps/hl -mvs/oic-oac/assets/pdf/oic-oac-eng.pdf (accessed 2014 Dec. 11).

4. Colley RC, Garriguet D, Janssen I, et al. Physical activity of Canadian adults: accelerometer results from the 2007 to 2009 Canadian Health Measures Survey. Health Rep 2011;22:7-14.

5. World Cancer Research Fund/American Institute for Cancer Research. Food, nutrition, physical activity, and the prevention of cancer: a global perspective. Washington: American Institute for Cancer Research; 2007. Available: www. aicr.org/assets/docs/pdf/reports/Second_Expert_Report.pdf (accessed 2014 Dec. 11).

6. Tardon A, Lee WJ, Delgado-Rodriguez M, et al. Leisure-time physical activity and lung cancer: a meta-analysis. Cancer Causes Control 2005;16:389-97.

7. Olsen CM, Bain CJ, Jordan SJ, et al. Recreational physical activity and epithelial ovarian cancer: a case-control study, systematic review, and meta-analysis. Cancer Epidemiol Biomarkers Prev 2007;16:2321-30.

8. Leitzmann MF. Physical activity and genitourinary cancer prevention. Recent Results Cancer Res 2011;186:43-71.

9. Liu Y, Hu F, Li D, et al. Does physical activity reduce the risk of prostate cancer? A systematic review and meta-analysis. Eur Urol 2011;60:1029-44.

10. Surveillance \& reporting: 2012 report on cancer statistics in Alberta. Edmonton: CancerControl Alberta, Alberta Health Services; 2015. Available: www .albertahealthservices.ca/assets/healthinfo/poph/hi-poph-surv-cancer-cancer -in-alberta-2012.pdf (accessed 2014 Dec. 11).

11. Parkin DM. 9. Cancers attributable to inadequate physical exercise in the UK in 2010. Br 7 Cancer 2011;105(Suppl 2):S38-41.

12. Olsen CM, Wilson LF, Nagle CM, et al. Cancers in Australia in 2010 attributable to insufficient physical activity. Aust N Z 7 Public Health 2015;39:458-63.

13. Brenner DR. Cancer incidence due to excess body weight and leisure-time physical inactivity in Canada: implications for prevention. Prev Med 2014;66: $131-9$.

14. Grundy A, Friedenreich CM, Poirier AE, et al. A methodologic framework to evaluate the number of cancers attributable to lifestyle and environment in Alberta. CMAJ Open 2016;4:E471-8.
15. Chao A, Connell CJ, Jacobs EJ, et al. Amount, type, and timing of recreational physical activity in relation to colon and rectal cancer in older adults: the Cancer Prevention Study II Nutrition Cohort. Cancer Epidemiol Biomarkers Prev 2004;13:2187-95.

16. Friedenreich C, Cust A, Lahmann PH, et al. Physical activity and risk of endometrial cancer: the European Prospective Investigation into Cancer and Nutrition. Int 7 Cancer 2007;121:347-55.

17. Lahmann PH, Friedenreich C, Schuit AJ, et al. Physical activity and breast cancer risk: the European Prospective Investigation into Cancer and Nutrition. Cancer Epidemiol Biomarkers Prev 2007;16:36-42.

18. Monninkhof EM, Elias SG, Vlems FA, et al. Physical activity and breast cancer: a systematic review. Epidemiology 2007;18:137-57.

19. Voskuil DW, Monninkhof EM, Elias SG, et al. Physical activity and endometrial cancer risk, a systematic review of current evidence. Cancer Epidemiol Biomarkers Prev 2007;16:639-48.

20. Béland Y. Health reports: Canadian community bealth survey - methodological overview. Ottawa: Statistics Canada; 2002;13:9-14. Cat no 82-003.

21. Kushi LH, Byers T, Doyle C, et al. American Cancer Society Guidelines on Nutrition and Physical Activity for cancer prevention: reducing the risk of cancer with healthy food choices and physical activity. [published erratum in CA Cancer 7 Clin 2007;57:66]. CA Cancer 7 Clin 2006;56:254-81, quiz 313-4.

22. Courneya KS, Friedenreich CM, editors. Physical activity and cancer. Berlin: Springer-Verlag Berlin Heidelberg; 2011.

23. Wolin KY, Yan Y, Colditz GA, et al. Physical activity and colon cancer prevention: a meta-analysis. Br 7 Cancer 2009;100:611-6.

24. Friedenreich CM, Cust AE. Physical activity and breast cancer risk: impact of timing, type and dose of activity and population subgroup effects. Br $\mathcal{F}$ Sports Med 2008;42:636-47.

25. Lynch BM, Friedenreich CM, Winkler EA, et al. Associations of objectively assessed physical activity and sedentary time with biomarkers of breast cancer risk in postmenopausal women: findings from NHANES (2003-2006). Breast Cancer Res Treat 2011;130:183-94.

26. Cust AE. Physical activity and gynecologic cancer prevention. Recent Results Cancer Res 2011;186:159-85.

27. Wolin KY, Tuchman H. Physical activity and gastrointestinal cancer prevention. Recent Results Cancer Res 2011;186:73-100.

28. Lynch BM, Neilson HK, Friedenreich CM. Physical activity and breast cancer prevention. Recent Results Cancer Res 2011;186:13-42.

29. Palacios S, Henderson VW, Siseles N, et al. Age of menopause and impact of climacteric symptoms by geographical region. Climacteric 2010;13:419-28.

30. Gold EB, Bromberger J, Crawford S, et al. Factors associated with age at natural menopause in a multiethnic sample of midlife women. Am 7 Epidemiol 2001;153:865-74.

31. Katzmarzyk PT, Gledhill N, Shephard RJ. The economic burden of physical inactivity in Canada. CMA7 2000;163:1435-40.

32. IARC handbooks of cancer prevention, volume 6: weight control and physical activity. Lyon (France): International Agency for Research on Cancer/World Health Organization; 2002.

33. Executive summary: policy and action for cancer prevention - food, nutrition, and physical activity, with an added US perspective. Washington: World Cancer Research Fund/American Institute for Cancer Research; 2009. Available: www.aicr.org/assets/docs/pdf/advocacypapers/WCRF_Policy_US_ Summary_final.pdf (accessed 2014 Dec. 11).

34. Friedenreich CM, Neilson HK, Lynch BM. State of the epidemiological evidence on physical activity and cancer prevention. Eur 7 Cancer 2010;46: 2593-604.

35. Brenner DR, Poirier AE, Grundy A, et al. Cancer incidence attributable to excess body weight in Alberta in 2012. CMA7 Open 2017;5:E330-6.

36. Behrens $G$, Leitzmann MF. The association between physical activity and renal cancer: systematic review and meta-analysis. Br 7 Cancer 2013;108: 798-811.

37. Inoue $M$, Tsugane $S$. Insulin resistance and cancer: epidemiological evidence. Endocr Relat Cancer 2012;19:F1-8.

Affiliations: Department of Cancer Epidemiology and Prevention Research (Brenner, Poirier, Grundy, Khandwala, McFadden, Friedenreich), CancerControl Alberta, Alberta Health Services; Department of Oncology (Brenner, Friedenreich), Cumming School of Medicine, University of Calgary; Department of Community Health Sciences (Brenner, Friedenreich), Cumming School of Medicine, University of Calgary, Calgary, Alta.

Contributors: Christine Friedenreich and Darren Brenner were responsible for the study conception. Anne Grundy, Christine Friedenreich, Darren Brenner, Farah Khandwala and Abbey Poirier contributed substantially to the study design and interpretation of the data. Alison $\mathrm{McFadden}$ and Anne Grundy were responsible for acquisition of the data. Farah Khandwala completed the analysis. All of the authors prepared the manuscript, approved the final version to be published and agreed to act as guarantors of the work. 
Funding: This project was funded by the Alberta Cancer Prevention Legacy Fund. Christine Friedenreich is supported by an Alberta Innovates - Health Solutions Health Senior Scholar Award and the Alberta Cancer Foundation Weekend to End Women's Cancer Chair in Breast Cancer at the University of Calgary. Darren Brenner is supported by a Career Development Award in Prevention from the Canadian Cancer Society Research Institute.

Acknowledgements: The authors gratefully acknowledge Laura McDougall from the Alberta Cancer Prevention Legacy Fund for her support and guidance. The authors also thank Bethany Kaposhi and Lorraine Shack from the Alberta Cancer Registry for providing cancer incidence data and the department of Data Integration, Measurement and Reporting at Alberta Health Services for enabling access to Canadian Community Health Survey data.

Supplemental information: For reviewer comments and the original submission of this manuscript, please see www.cmajopen.ca/content $/ 5 / 2 /$ E338/suppl/DC1 